\title{
Niche generation
}

\author{
Jo Chikwe, MD
}

From the Department of Cardiovascular Surgery, Icahn School of Medicine at Mount Sinai, New York, NY.

Disclosures: Author has nothing to disclose with regard to commercial support.

Received for publication Nov 12, 2015; accepted for publication Nov 16, 2015; available ahead of print Dec 11, 2015 .

Address for reprints: Jo Chikwe, MD, Icahn School of Medicine at Mount Sinai, Cardiovascular Surgery, 1190

Fifth Ave, New York, NY 10029 (E-mail: Joanna.chikwe@mountsinai.org).

J Thorac Cardiovasc Surg 2016;151:640-1

$0022-5223 / \$ 36.00$

Copyright (c 2016 by The American Association for Thoracic Surgery

http://dx.doi.org/10.1016/j.jtcvs.2015.11.025

Kilic's article ${ }^{1}$ in this issue of the Journal contains well-intentioned, practical advice for newly graduating surgeons, which is based on the premise that the ultimate goal is to become a "go-to surgeon" in a particular niche. He recommends training geared toward rapid acquisition of marketable skills. In his words, "Be selfish and start thinking like a business person, with the product being you."

$\mathrm{He}$ is preaching to the converted: half the residents surveyed in US cardiothoracic training programs plan to pursue additional training, primarily to develop niche practices. $^{2}$ Is this a pragmatic approach to today's job market? Kilic ${ }^{1}$ describes "aortic, valve, arrhythmia, and heart failure" as the 4 top growth areas, but most employers are not actively looking for these skill sets. Of 40 cardiac surgery jobs advertised in the US earlier this year, three-quarters requested specific expertise. ${ }^{3}$ Least commonly requested was arrhythmia and transcatheter valve experience ( 5 positions), followed by valve and heart failure skills (8 positions). In fact, the most sought-after expertise for adult cardiac surgeons was vascular and thoracic surgery (16 positions). According to this informal poll, the most marketable niche may be the one occupied by the accomplished generalist. So it is particularly intriguing that the percentage of residents seeking a mixed cardiothoracic practice fell by two-thirds to a mere $16 \%$ between 2003 and 2014 . $^{2}$

Why such enthusiasm for an early specialist niche practice? Perhaps residents are influenced by their mentors-our specialty leaders. These titans of thoracic surgery, however, spent decades carving refined practices out of the broadest bases. And early-career surgeons universally recognized for niche expertise are equally difficult to emulate-they are the unicorns of thoracic surgery, mythical beasts from a distant paradise (possibly a mirage) of exceptional training, mentorship, and timing. In a thoughtful distillation of career advice from 20 leaders of cardiothoracic surgery, every surgeon emphasized the paramount importance of broad clinical and technical proficiency, most advocated eventually focusing on specific areas, but only a handful recommended that new graduates immediately pursue specialist niches. ${ }^{4}$

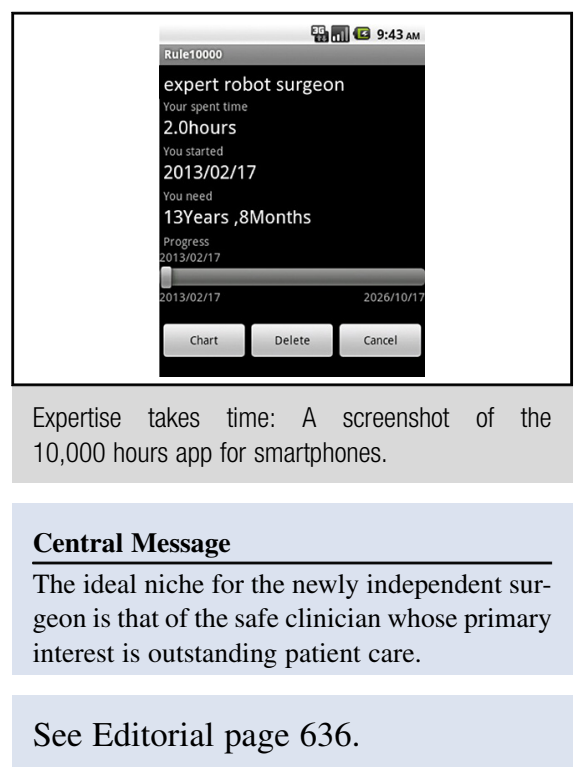

Early specialization is not a new concept. Perhaps the greatest surgeon educator of our time, David Sabiston, described the advantages of earlier specialization in his 1969 monograph, "A Continuum in Surgical Education: A Proposal for Maximal Flexibility in Career Planning by Selective Experiences in Medical School and Graduate Training" : "[W]ith adequate planning in the elective years of medical school and progression to an individualized residency the surgeon produced resembles a second or third year member of the junior faculty." The organization of Sabiston's residency program shares superficial similarities with modern programs-outweighed by the greater complexity of contemporary practice and steep reductions in the hours residents now work. This has reduced exposure to the one element that, in Sabiston's opinion, was the sole guarantee of successful surgical training and early acquisition of specialist skills. Quoting Sir William Osler, he described it as, "the open sesame to every portal, the great equalizer in the world... The stupid man among you it will make bright, the bright man brilliant, and the brilliant student steady...Work remains the master-word, and substitutes are destined to failure." 5

How much work is needed to develop expertise? Despite burgeoning educational research, theory and regulations, we know very little about how much and what kind of training is required to develop competency, let alone expertise. The " 10,000 hours rule" is one attempt to summarize this entire field of research (Figure 1). Invented and popularized by Malcolm Gladwell in his book Outliers: The Story of Success, ${ }^{6}$ the rule is loosely based on research 


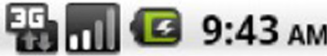

\section{Rule10000}

\section{expert robot surgeon}

Your spent time

\section{0hours}

You started

\section{3/02/17}

\section{You need \\ 13Years ,8Months}

\section{Progress \\ 2013/02/17}

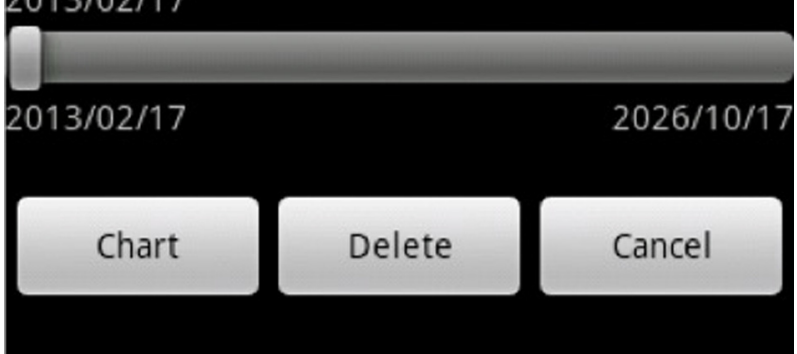

FIGURE 1. Expertise takes time: A screenshot of the 10,000 hours app for smartphones.

by K. Anders Ericsson, who reports that it is primarily the amount of "deliberate practice" (not just mechanical repetition) that differentiates the average from the elite across occupations as diverse as surgeons, fighter pilots, and professional musicians. ${ }^{7,8}$ Ericsson presented his work at the Joint Council on Thoracic Surgery Education 2010 Educate the Educators program. He writes: “There are no shortcuts. It will take you at least a decade to achieve expertise, and you will need to invest that time wisely, by engaging in "deliberate" practice-practice that focuses on tasks beyond your current level of competence and comfort. You will need a well-informed coach not only to guide you through deliberate practice but also to help you learn how to coach yourself."

So what should the graduating cardiac resident do? Kilic ${ }^{1}$ suggests spending some months concentrating on "mastery of a particular technique." But this is too narrow a vision of what our many outstanding residents are capable of, and much too limited in scope to sustain an entire clinical practice. Irrespective of your first job title, take the position with the most operating, teaching, and mentorship you can-it will enable you from the outset to achieve real clinical and operative proficiency across the main domains of cardiac surgery (not just one technique) and to develop genuine mastery in the areas you enjoy most - with another 10,000 hours or so of practice.

\section{References}

1. Kilic A. How to develop a niche: focus on adult cardiac surgery. $J$ Thorac Cardiovasc Surg. 2016;151:636-9.

2. Stephens EH, Odell D, Stein W, LaPar DJ, DeNino WF, Aftab M, et al. A decade of change: training and career paths of cardiothoracic surgery residents 2003 to 2014. Ann Thorac Surg. 2015;100:1305-14.

3. CTSNet: The Cardiothoracic Surgery Network. Career Center Home: Job Search. Available at: http://jobs.ctsnet.org/c/search_results.cfm?site_id=8155. Accessed July 30, 2015.

4. Grondin SC. Building a successful career: advice from leaders in thoracic surgery. Thorac Surg Clin. 2011;21:395-415.

5. Sabiston DC Jr. A continuum in surgical education: a proposal for maximal flexibility in career planning by selective experiences in medical school and graduate training. Surgery. 1969;66:1-14.

6. Gladwell M. Chapter 2: the 10,000 hour rule. In: Gladwell M, ed. Outliers: the story of success. New York: Little, Brown and Company; 2008:35-68.

7. Ericsson KA, Prietula MJ, Cokely ET. The making of an expert. Harv Bus Rev. 2007;85:113-21. 193 .

8. Ericsson KA, Krampe RT, Tech-Romer C. The role of deliberate practice in acquisition of expert performance. Psychol Rev. 1993;3:363-401. 